\title{
A CONSTITUCIONALIZAÇÃO DO DIREITO PENAL E A LIMITAÇÃO TEMPORAL DAS MEDIDAS DE SEGURANÇA
}

\author{
Daniela Carvalho Almeida da Costa* \\ Gabriela Silva Paixão ${ }^{* *}$
}

\begin{abstract}
RESUMO:
A medida de segurança não possui prazo legal máximo para sua duração, o qual depende da emissão de laudo psiquiátrico de cessação de periculosidade. As internações dos inimputáveis muitas vezes ultrapassavam trinta anos e adquiriam caráter perpétuo. Nesse cenário, os tribunais superiores começaram a decidir a favor da limitação temporal do instituto. Parte-se da hipótese, em método de revisão bibliográfica e coleta de dados jurisprudenciais, de que o movimento de constitucionalização do Direito Penal e a reinterpretação da legislação ordinária à luz dos direitos fundamentais foram os fundamentos teóricos para esse giro jurisprudencial. Hipótese confirmada nas conclusões do presente artigo.

Palavras-chave: Medida de segurança. Tribunais superiores. Limitação temporal. Constitucionalização. Direito penal.

\section{CONSTITUCIONALIZATION OF CRIMINAL LAW AND PSYCHIATRIC DETAINMENT'S MAXIMUM LENGTH}

\begin{abstract}
:
There is no established time limit for the security measures, it will be determined by a clinical report establishing the end of the unimputable risk level. Consequently, custodies have lasted for more than thirty years and became perpetual. In this scenario, the superior courts began to attribute a time limit to this institute. Therefore, the hypothesis, in a revision of bibliography and jurisprudencial collect data method, is that the constitutionalization of criminal law and the reinterpretation of ordinary legislation based in constitutional values are the theoretical foundations of this jurisprudencial turn. Acknowledged in the conclusions of the present article.
\end{abstract}

Key words: Security measures. Superior courts. Time limit. Constitutionalization. Criminal law.

\section{INTRODUÇÃO}

A medida de segurança é um instituto que sempre esteve à margem da pena privativa de liberdade, e do qual muito pouco se fala. Por conta disso, a realidade de sua execução, seja na internação em um Hospital de Custódia e Tratamento Psiquiátrico (HCTP), seja na

\footnotetext{
*Doutora e Mestre em Direito Penal e Processo Penal pela USP. Especialista em Direito Penal e Processual Penal pela Universidad de Salamanca. Professora Associada da UFS. E-mail: dancacosta@ @otmail.com.

${ }^{*}$ Graduada em Direito pela Universidade Federal de Sergipe. Pós-graduada em Filosofia e Teoria do Direito pela PUC-Minas. Mestranda no Programa de Pós-Graduação em Direito da Universidade Federal de Sergipe. Email: gabi.spaixao1994@gmail.com.
} 
compulsoriedade de um tratamento ambulatorial, costuma passar despercebida no imaginário popular, e até mesmo no cotidiano dos operadores de direito.

A despeito disso, não é modelo de custódia estatal recente, mas que remonta, no Brasil, ao início do século XX, com a criação dos antigos manicômios judiciários. Um acordo entre a ciência jurídica e a psiquiatria, ambientado no contexto do positivismo criminológico, que proporcionou a apropriação do tratamento dos indivíduos com transtornos mentais em conflito com o sistema de justiça criminal. Aplicando a eles a mesma lógica punitivista definidora.

O regramento contido no Código Penal sobre uma espécie de sanção penal aplicada aos inimputáveis por doença mental passou a chamar a atenção a partir do momento em que alguns dos seus dispositivos mostraram-se contraditórios aos objetivos constitucionais de promoção da dignidade da pessoa humana e limitação do poder punitivo estatal. Em especial a ausência de tempo máximo para seu cumprimento, o qual, em muitos casos, ultrapassava trinta anos de custódia. Situação que apenas cronifica o transtorno mental e reforça o rompimento dos laços afetivos e sociais dos pacientes judiciários.

Nesse cenário problemático, os direitos e garantias fundamentais de matéria penal previstos na Constituição Federal de 1988, a exemplo da vedação das penas de caráter perpétuo, passaram a ser argumentos para julgados dos tribunais superiores que flexibilizavam a ausência de prazo máximo para a medida de segurança. Movimento esse que, conforme hipótese apresentada neste trabalho, retira fundamento teórico no processo de constitucionalização do Direito Penal e de obrigatoriedade de incidência de seus valores e dispositivos na interpretação e aplicação desse ramo.

Pretende-se, então, fazer um percurso de contextualização desse movimento teórico, doutrinário e filosófico, até sua incidência no sistema de justiça criminal. Em um segundo momento, há a necessidade de caracterizar a medida de segurança e suas hipóteses de incidência, de forma a reconhecer o caráter aflitivo desse instituto e seu potencial de restrição a direitos e garantias fundamentais do indivíduo. E, com isso, cotejar a sua existência e aplicação com os objetivos constitucionais em matéria penal, no âmbito de julgados do STF e STJ que tratam da previsão de prazo máximo para sua duração, seja de trinta anos, seja da pena abstratamente cominada ao delito.

Para tanto, a pesquisa partiu do método de revisão bibliográfica de escritos que tratam, principalmente, do tema da constitucionalização do direito e da medida de segurança. Além 
da coleta de dados jurisprudenciais que subsidiarão o entendimento do problema formulado.

\section{O MOVIMENTO DE CONSTITUCIONALIZAÇÃO DO DIREITO PENAL BRASILEIRO}

No Brasil, o ordenamento jurídico passou por um processo de amadurecimento doutrinário após a redemocratização nacional, o que culminou na promulgação da Constitutição Federal de 1988. A confecção de um documento formal que orienta a atuação do Estado e a proteção de seus cidadãos faz parte de um processo maior de mudanças teóricas e filosóficas na ciência jurídica, que possibilitaram a expansão do direito constitucional para as demais áreas, além de colocá-lo como norte axiológico das interpretações legislativas e jurídicas (BARROSO, 2005, p. 2-3).

No campo filosófico, a constitucionalização do Direito representa a influência do póspositivismo, o qual buscou resgatar aspectos de ordem moral para a construção de uma teoria da justiça condizente com os anseios de proteção da dignidade da pessoa humana, em uma sociedade devastada pela $2^{\mathrm{a}}$ Grande Guerra, mas em busca de segurança jurídica para sua reconstrução. Nesse panorama, observa-se:

a atribuição de normatividade aos princípios e a definição de suas relações com valores e regras [...] e o desenvolvimento de uma teoria dos direitos fundamentais sobre o fundamento da dignidade humana (BARROSO, 2005, p. 6)

O pós-positivismo, que tem como referências Rawls e Dworkin, surgiu a partir da busca pela reintegração de conteúdos humanistas na teoria do Direito, após um período conturbado de dominação da corrente positivista, a qual, sem sucesso, tentou apartar o conceito jurídico dos ideais de justiça (PILON; DUTRA, 2003, p. 183-184).

No campo teórico, o neoconstitucionalismo, então, transformou o papel da Constituição frente ao sistema normativo do país, o que Barroso aponta como sendo o reconhecimento de sua força normativa ${ }^{1}$, a expansão de sua jurisdição com o controle de constitucionalidade e a construção de uma nova teoria da interpretação jurídica. Esta última representada por princípios instrumentais, os quais direcionam a intrepretação e aplicação de outras normas, a exemplo da supremacia da Constituição, da unidade, da razoabilidade e da ponderação (2005, p. 6-11). São os denominados postulados normativos ou metanormas

\footnotetext{
${ }^{1}$ Esse conceito foi formulado pelo professor alemão Konrad Hesse, em sua obra "A força normativa da Constituição" (1959).
} 
(ÁVILA, 2005, p. 88).

Os três aspectos listados acima deram origem a movimentos de duas ordens, mas que são complementares: a incorporação no texto formal de temas antes tratados apenas pelas normas infraconstitucionais e a irradiação do conteúdo material das normas constitucionais para todo o sistema jurídico (BARROSO, 2005, p. 16).

Esse é um fenômeno que, no Brasil, só foi possível a partir da conjugação de um cenário político de redemocratização pós Ditadura Militar e da confecção de uma carta formal de direitos e garantias fundamentais, em busca da construção de uma sociedade livre, plural e segura.

É por meio de um Estado Democrático de Direito que tais objetivos podem ser alcançados, tendo em vista que a soberania popular é pressuposto para a organização estatal e direção das atividades que visem a superação de desigualdades, e para a rejeição de instrumentos arbitrários e autoritários de poder (SOARES, 2017, p. 307-308). Ao fim, o objetivo é a concretização da proteção fundamental já escrita.

Nesse contexto, o Direito Penal, como os demais ramos, sofreu influência do movimento de constitucionalização do Direito, tanto no sentido de que a $\mathrm{CF} / 88$ passou a prever direitos e garantias fundamentais atinentes à matéria, quanto no fato de que as normas constitucionais são vinculantes, de observância obrigatória pelo legislador ordinário e pelos julgadores.

Para Feldens, a influência da Constituição Federal no Direito Penal perpassa três níves: “a) a Constituição como limite material do Direito Penal; b) a Constituição como fonte valorativa do Direito Penal; e c) a Constituição como fundamento normativo do Direito Penal” (2007, p. 837).

Dentre as previsões normativas sobre a matéria contida no texto fundamental, as quais perpassam a instituição de competências, inviolabilidades, mandados de criminalização, dentre outros, está o que se considera o epicentro da conexão entre os dois ramos: os direitos e garantias fundamentais (FELDENS, 2007, p. 837). Especialmente as proteções do indivíduo que incidem no momento de aplicação da pena.

É neste ponto de confluência que reside o dever de reinterpretação da aplicação da medida de segurança pela filtragem constitucional. Um instituto formalmente penal que implica restrições à liberdade e integridade do indíviduo também deve fazer incidir as garantias de não perpetuidade da pena e de isonomia, de forma a preservar o centro axiológico 
do sistema normativo brasileiro: a dignidade da pessoa humana.

\section{A MEDIDA DE SEGURANÇA COMO SANÇÃO PENAL}

A medida de segurança é instituto de Direito Penal disciplinado nos artigos 96 a 99 do $\mathrm{CP}$, além de ter previsão legislativa também no CPP e na Lei de Execução Penal. Destina-se, precipuamente, aos considerados inimputáveis por doença mental ao tempo do cometimento do delito, mas também há possibilidade de sua aplicação nos casos de superveniência de pertubação mental durante a execução da pena privativa de liberdade ${ }^{2}$.

Antes de defini-la, é importante trazer alguns conceitos jurídicos que lhe dão origem, seriam eles: a culpabilidade, a inimputabilidade e a irresponsabilidade penal. É a partir dessas construções dogmáticas, extraídas da teoria do crime, que se justifica a impossibilidade de aplicação de pena ao tido por louco-criminoso e elege-se a medida de segurança como consequência penal.

O conceito analítico de crime, fruto de uma construção histórica da dogmática penal, corresponde a uma ação típica, antijurídica e culpável, e no Brasil tem como substrato teórico o finalismo welzeniano, em especial suas contribuições para a inclusão de elementos subjetivos no tipo e a normatização da culpabilidade (BITENCOURT, 2016, p. 276-279). Cada uma dessas categorias é independente e sucessiva, o que faz concluir que, para se chegar ao patamar da culpabilidade, deve-se estar comprovada a prática de um injusto penal.

O terceiro elemento do crime surgiu com a função de limitar a imposição da pena por parte do Estado, o qual deveria analisar a motivação do agente ao cometer o crime (BITENCOURT, 2016, p. 437). Com o advento do finalismo, os elementos subjetivos de culpa e dolo transpuseram-se para a tipicidade penal, e, com isso, restou na culpabilidade características de ordem puramente normativa. A possibilidade de reprovação do agir dependeria da comprovação da exigibilidade de conduta diversa, da potencial consciência de ilicitude e da imputabilidade, sendo esta última o atual objeto de estudo (ZAFFARONI; PIERANGELI, 2011, p. 524-525)

O Código Penal conceitua os elementos da culpabilidade em sua forma negativa, enquanto excludentes do último elemento do delito. Portanto, no caso da imputabilidade, pode-se inferir que ela é o contrário daquilo que preconiza o art. 26 do CP: imputável é o indivíduo que era, ao tempo da ação, inteiramente capaz de entender a ilicitude de sua prática

\footnotetext{
${ }^{2}$ Ver art. 183 da Lei $n^{\circ} 7.210 / 1984$.
} 
e de determinar-se de acordo com esse entendimento.

Comprovar empiricamente essa capacidade psíquica era inviável doutrinariamente, uma vez que implicaria em fundamentá-la exclusivamente no livre-arbítrio, conceito que se aproxima da metafísica e se distancia de uma deontologia jurídica. Optou-se, então, por trazer um elemento objetivo ao termo: a motivação pela norma jurídica (OLIVÉ ET AL, 2011, p. 462). Para Zaffaroni e Pierangeli, "ao não ser motivado na norma, quando podia e lhe era exigível que o fizesse, o autor mostra uma disposição interna contrária ao direito" (2011, p. 521)

Além disso, a inimputabilidade possui caráter biopssicológico, pois, ao tempo do fato, devem coexistir a doença mental ou o desenvolvimento mental incompleto ou retardado (aspecto biológico), e a incapacidade de compreensão do caráter ilícito do ato ou de autodeterminação (aspecto psicológico), sem os quais não se pode falar em irresponsabilidade penal.

O último conceito jurídico relacionado à medida de segurança é a própria responsabilização penal, a qual surge como consequência lógica do preenchimento dos três elementos: o fato típico, antijurídico e culpável. A partir deste ponto, há um autorizativo legal para o Estado atribuir uma medida sancionatória ao agente, caso não esteja presente algumas das hipóteses de extinção da punibilidade.

O problema reside no fato de que, em que pese a inimputabilidade por doença mental afastar a culpabilidade, na prática há uma efetiva responsabilização penal. E, pior, de tipo objetiva, já que não se indaga a respeito da culpa na correlação entre ação, resultado e nexo causal. Há previsão de uma necessária consequência jurídica para o ato, que é a própria medida de segurança, em que pese atribuírem caráter terapêutico (FURHER, 2000, p. 81-82).

Existe, com isso, uma diferença de aplicação entre as dirimentes de culpabilidade. A coação irresistível, a obediência hierárquica, o erro de proibição inevitável e as descriminantes putativas efetivamente geram uma irresponsabilização penal, posto que não há qualquer consequência jurídica para o autor. Comprovadas durante o processo, implicam em absolvição integral. Com a inimputabilidade por doença mental é diferente, a absolvição é imprópria (ou seja, não há absolvição) e o agente é submetido a uma restrição de liberdade, em forma de internação ou tratamento ambulatorial compulsórios.

Diante do que foi dito, conclui-se que a imposição da medida de segurança está condicionada à existência de três pressupostos: a prática de um injusto penal, a ausência de 
imputabilidade plena e a periculosidade presumidade do agente (BITENCOURT, 2016, p. $864-865)^{3}$.

Da leitura do art. 96 do CP infere-se que a medida de segurança é gênero de duas espécies: a detentiva e a restritiva. A primeira é imposta para os crimes apenados com reclusão, e importa em internação no HCTP. A segunda, para aqueles apenados com detenção, e pode implicar em submissão a tratamento ambulatorial ${ }^{4}$.

A legislação penal determina que a internação (e também o tratamento ambulatorial) terão prazo máximo indeterminado, dependentes do exame de cessação de periculosidade, o qual será realizado após o transcurso do prazo mínimo estabelecido entre um e três anos. Após, será repetido no mínimo anualmente ${ }^{5}$. Há, neste ponto, duas questões que precisam ser destrinchadas.

Primeiramente, a partir daí há uma transformação da presunção absoluta de periculosidade para relativa, uma vez que a internação dependerá de efetiva prova pericial da existência de perigo, diferentemente do momento de imposição da medida, quando basta a constatação do injusto e da situação de inimputabilidade (FUHRER, 2000, p. 149).

A outra questão, e a que mais importa a este trabalho, é a inexistência de prazo máximo para a duração da medida de segurança. Uma internação em um HCTP pode se transformar em uma segregação de caráter perpétuo, já que a legislação não prevê limite temporal para sua execução ${ }^{6}$. O problema quanto à ausência de prazo é que, apesar de não ser

\footnotetext{
${ }^{3}$ Há fortes críticas tecidas à atribuição de periculosidade ao inimputável, especialmente em relação à presunção absoluta quando do exame psiquiátrico inicial. Contudo, o presente trabalho não comporta maiores digressões sobre o tema, motivo pelo qual remetemos o leitor a JACOBINA, Paulo Vasconcelos. Direito Penal da Loucura: medida de segurança e reforma psiquiátrica. Brasília: ESMPU, 2008 e MATTOS, Virgílio. Canhestros caminhos retos: notas sobre a segregação prisional do portador de sofrimento mental infrator. In: Revista Brasileira de Crescimento e Desenvolvimento Humano, São Paulo, v. 20, n. 1, p. 51-60, 2010.

${ }^{4}$ Neste ponto, destacamos recente decisão do STJ no sentido de não interpretar literalmente o contido no art. 97 do $\mathrm{CP}$ e, com lastro em princípios de razoabilidade e proporcionalidade, determinar que cabe ao julgador analisar o caso concreto para averiguar qual tipo de medida de segurança é adequada, independentemente de a pena em abstrato ser de reclusão ou detenção. Vide o julgado EREsp nº 998.128 - MG.

$5 \S 1^{\circ}$ e $2^{\circ}$, art. $97, \mathrm{CP}$.

${ }^{6}$ Histórias de confinamento em Hospitais Psiquiátricos por mais de trinta anos, infelizmente, são verdadeiras. A segregação de longa permanência em instituições totais rompe laços familiares e comunitários, além de impactar na autonomia do indivíduo, o que dificulta sua reinserção na sociedade (GOFFMAN, 2015, p. 289). Com a falta de políticas públicas para acolhimento dos egressos, muitas vezes a opção encontrada é manter o custodiado internado, mesmo quando já há laudo de cessação de periculosidade. Nesse sentido, remetemos à leitura de DINIZ, Debora; BRITO, Luciana. "Eu não sou presa de juízo, não": Zefinha, a louca perigosa mais antiga do Brasil. In: História, Ciências, Saúde - Manguinhos, Rio de Janeiro, v.23, n.1, jan.-mar. 2016, p. 113-129 e DINIZ, Débora. A custódia e o tratamento psiquiátrico no Brasil: Censo 2011. Brasília: Editora Universidade de Brasília, 2011.
} 
a medida de segurança pena em si, ela é espécie de sanção penal e possui inegável caráter aflitivo. A internação em um HCTP, um misto de manicômio e prisão, dificilmente atinge suas finalidades terapêuticas declaradas.

Como aponta Weigert, a responsabilização penal no Brasil consiste, a priori, na utilização de dois tipos de medidas estatais, a pena privativa de liberdade e as medidas, socioeducativas e de segurança. Nesta última, inflige-se um castigo ao indivíduo motivado por sua própria forma de ser, e não pelo ato que cometeu (2017, p. 75).

A medida de segurança é formalmente penal, e nisso não há dúvidas. Em que pese eventual entendimento pela ausência de conteúdo material no instituto, ele não obsta que se reconheça a restrição de liberdade e de direitos fundamentais que ela promove, inclusive de forma mais gravosa que a prisão, em muitos aspectos (ZAFFARONI, 2011, p. 733).

Diante desse cenário, os Tribunais Superiores passaram a impor prazo máximo para a execução desse instituto, tendo por base, como será explicitado no capítulo seguinte, a incidência das normas constitucionais de proteção do indivíduo e limitação do poder punitivo estatal.

\section{A CONSTITUCIONALIZAÇÃO DO DIREITO PENAL E AS DECISÕES DO STF E STJ SOBRE A LIMITAÇÃO TEMPORAL DAS MEDIDAS DE SEGURANÇA}

A vedação constitucional a penas de caráter perpétuo e cruéis, bem como a proteção à integridade física e moral do apenado ${ }^{7}$, estimularam críticas à ausência de limitação temporal na execução da medida de segurança. Como dito, a consideração do instituto como espécie do gênero sanção penal cunhou o entendimento de que era necessário estabelecer prazo máximo para o seu cumprimento, em similitude à pena privativa de liberdade.

A extinção da medida segurança não poderia depender apenas da emissão de laudo pericial de cessação de periculosidade, pois, em muito casos, isso importava na internação do indivíduo por períodos superiores a trinta anos, em afronta também à legislação penal ordinária $^{8}$. Nesse sentido, duas vertentes jurisprudenciais surgiram: uma encabeçada pelo STF e outra pelo STJ, esta última dando origem à súmula $n^{\circ} 527$.

Os dados jurisprudenciais coletados para a confecção do presente tópico foram obtidos nos sítios eletrônicos do Supremo Tribunal Federal [portal.stf.jus.br] e do Superior Tribunal

\footnotetext{
${ }^{7}$ Alínea b, inciso XLVII e inciso XLIX, do art. $5^{\circ}$, da CF

${ }^{8}$ Art. 75, CP. Ressalte-se a alteração promovida pelo pacote anticrime (Lei no 13.964/2019) que aumentou o limite máximo das penas privativas de liberdade para quarenta anos.
} 
de Justiça [www.stj.jus.br].

No portal do STF, no campo denominado "jurisprudência" foram inseridas as expressões "medida de segurança" e "trinta anos", além de aplicado o filtro de classe para "habeas corpus". A pesquisa apontou a existência de seis processos com essas características: HC n 84.219/SP; n 97.621/RS; n 98.360/RS; n 107.432/RS; e n 107.777/RS. Já na página do STJ, nos campos "jurisprudência" e "súmula anotada", foi inserida a expressão "súmula 527". O documento apontou a existência de sete habeas corpus considerados como precedentes para a confecção do verbete e julgados após 16/04/2012 (data da publicação do acórdão no $\mathrm{HC} \mathrm{n}^{\circ} 107.777 / \mathrm{RS}$, e mais recente entendimento do STF): HC $\mathrm{n}^{\circ} 156.916 / \mathrm{RS} ; \mathrm{n}^{\circ}$ 91.602/SP; $n^{\circ}$ 167.136/DF; no 251.296/SP; nº 285.953/RS; no 269.377/AL; e no 286.733/RS.

A análise correspondeu à leitura do inteiro teor dos acórdãos proferidos nos processos apontados nas buscas. E optou-se por trazer neste tópico os argumentos apresentados em apenas alguns deles e que expressam o entendimento das Cortes Superiores sobre a limitação temporal da medida de segurança. A escolha por mencionar parcialmente os julgados foram os fatos de que as fundamentações se repetiam e a limitação do presente trabalho. Priorizouse, também, os julgados tidos por inaugurais da temática.

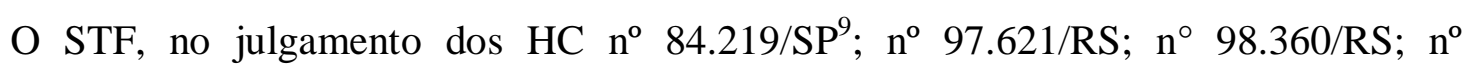

\begin{abstract}
${ }^{9}$ EMENTA: LIMINAR MEDIDA DE SEGURANÇA - ULTRAPASSAGEM DO PRAZO MÁXIMO DE CUSTÓDIA DE TRINTA ANOS - EXTINÇÃO PRETENDIDA - LIMINAR - TRANSFERÊNCIA PARA HOSPITAL PSIQUIÁTRICO DA REDE PÚBLICA - DEFERIMENTO. 1. De acordo com a inicial de folha 2 a 7, a paciente encontra-se sob a custódia do Estado, embora internada em hospital, há mais de trinta anos, estando excedido, assim, o prazo máximo previsto no artigo 75 do Código Penal. No ato apontado como configurador de constrangimento, a Sexta Turma do Superior Tribunal de Justiça proclamou que "a lei penal não prevê limite temporal máximo para o cumprimento da medida de segurança, somente condicionada à cessação da periculosidade do agente". Articula-se com o disposto não só no citado artigo 75 do Código Penal, como também com a norma do artigo 183 da Lei de Execucoes Penais, evocando-se precedentes do Superior Tribunal de Justiça, em processos nos quais funcionaram como relatores os ministros José Arnaldo da Fonseca e Felix Fischer, no sentido de ter-se a medida de segurança balizada pela duração da pena imposta ao réu. Sustenta-se que, mesmo persistindo a doença mental e havendo necessidade de tratamento após a declaração da extinção da punibilidade, este deve ocorrer em hospital psiquiátrico, cessada a custódia. Requer-se a concessão de medida acauteladora que viabilize a remoção da paciente para hospital psiquiátrico da rede pública, onde deverá ser submetida a tratamento adequado de forma a possibilitar a futura transferência para colônia de desinternação progressiva, ressaltando-se que, embora a internação haja perdurado por todo esse tempo, o tratamento mostrou-se ineficaz. O pleito final formulado visa à extinção da medida de segurança, providenciando-se, se não acolhido o pedido de concessão de liminar, a transferência para hospital psiquiátrico. À inicial juntaram-se os documentos de folha 8 a 133.2. Observe-se a garantia constitucional que afasta a possibilidade de ter-se prisão perpétua. A tanto equivale a indeterminação da custódia, ainda que implda sob o ângulo da medida de segurança. O que cumpre assinalar, na espécie, é que a paciente está sob a custódia do Estado, pouco importando o objetivo, há mais de trinta anos, valendo notar que o pano de fundo é a execução de título judiciário penal condenatório. $\mathrm{O}$ artigo 75 do Código Penal há de merecer o empréstimo da maior eficácia possível, ao preceituar que o tempo de cumprimento das penas privativas de liberdade não pode ser superior a trinta anos. Frise-se, por
\end{abstract}


107.432/RS; e $\mathrm{n}^{\mathrm{o}}$ 107.777/RS, entendeu que a duração da medida de segurança não poderia exceder o prazo de trinta anos, previsto na legislação infraconstitucional.

Da análise do inteiro teor do julgado que inaugurou o entendimento, publicado em 2005, observa-se que a fundamentação utilizada pelo julgador já trazia elementos de ordem constitucional, conferindo ao $\S 1^{\circ}$ do artigo 97 do $\mathrm{CP}$ “interpretação teleológica e sistemática, atentando-se para o limite máximo de trinta anos fixado pelo legislador ordinário, tendo em conta a regra primária vedadora da prisão perpétua" (BRASIL, 2005, p. 6)

Outrossim, importante destacar a justificativa apontada para aplicação de regra inicialmente prevista para a pena privativa de liberdade à medida de segurança. $O$ então relator Ministro Marco Aurélio apontou a custódia do paciente pelo Estado e a sua origem a partir de um título judiciário penal condenatório, como motivos ensejadores da aplicação da vedação constitucional à pena de caráter perpétuo ao instituto. Ademais, construiu raciocínio de que a medida, enquanto substituta da prisão, não pode ser mais gravosa que ela, em nome do princípio da isonomia (BRASIL, 2005, p. 6).

Em posicionamento semelhante foi o voto vista dado pelo então Ministro Sepúlveda Pertence, que consignou o caráter punitivo e de sanção da medida de segurança, à semelhança da pena de prisão (BRASIL, 2005, p. 13)

O posicionamento do STF, contudo, a despeito de limitar a execução da medida de segurança em trinta anos, manteve a diferenciação para a execução da pena de prisão em relação à cominação de prazos máximo em abstrato. Na prática, um inimputável que cometesse um fato típico e antijurídico de roubo simples, por exemplo, poderia ficar segregado por mais de dez anos, caso não houvesse laudo pericial liberatório antes disso. Enquanto um imputável que cometesse roubo simples não poderia ficar preso por mais de dez anos, nos termos do art. 157 do CP.

Nesse sentido, o STJ ampliou o entendimento já exarado pelo STF para estabelecer

oportuno, que o artigo 183 da Lei de Execução Penal delimita o período da medida de segurança, fazendo-o no que prevê que esta ocorre em substituição da pena, não podendo, considerada a ordem natural das coisas, mostrar-se, relativamente à liberdade de ir e vir, mais gravosa do que a própria apenação. É certo que o $\S 1^{\circ}$ do artigo 97 do Código Penal dispõe sobre prazo da imposição da medida de segurança para inimputável, revelando-o indeterminado. Todavia, há de se conferir ao preceito interpretação teleológica, sistemática, atentando-se para o limite máximo de trinta anos fixado pelo legislador ordinário, tendo em conta a regra primária vedadora da prisão perpétua. A não ser assim, há de concluir-se pela inconstitucionalidade do preceito.3. Defiro a liminar pleiteada para que se implemente a remoção da paciente, implicando a internação desta em hospital psiquiátrico comum da rede pública.4. Estando nos autos as peças indispensáveis ao julgamento do habeas, colha-se o parecer da Procuradoria Geral da República.5. Publiquese. Brasília, 24 de abril de 2004. Ministro MARCO AURÉLIO Relator (STF - HC: 84219 SP, Relator: Min. MARCO AURÉLIO, Data de Julgamento: 24/04/2004, Data de Publicação: DJ 03/05/2005 PP-00011) 
também prazo específico aplicado à execução da medida de segurança, a saber a pena máxima abstratamente cominada ao delito, o que gerou a publicação da súmula $\mathrm{n}^{\mathrm{o}} 527^{10}$.

No julgamento do $\mathrm{HC} \mathrm{n}^{\mathrm{o}} 286.733 / \mathrm{RS}^{11}$, o qual precedeu a publicação do verbete, observa-se no voto da relatora Ministra Maria Thereza de Assis Moura a utilização do princípio da isonomia para afastar o tratamento mais severo dado ao inimputável que cumpre medida de segurança, bem como o da proporcionalidade, na vertente da proibição de excesso, para limitar o tempo de aplicação do instituto, independentemente da cessação de periculosidade do agente (BRASIL, 2014, p. 6).

A proporcionalidade como proibição ao excesso apresenta-se como recurso interpretativo do julgador em sua margem de atuação no controle do poder punitivo estatal. De acordo com Pulido, o excesso a ser refutado é identificado pelos subprincípios da adequação, necessidade e proporcionalidade em sentido estrito. $\mathrm{O}$ primeiro a indicar que a medida punitiva deve ser adequada para promover os valores constitucionais. O segundo no sentido de não existir outra restrição menos invasiva que promova o mesmo fim. E o terceiro como equivalência entre a proteção do bem promovida pela restrição e a afetação da liberdade que ela ocasiona (2007, p. 822-824)

A isonomia, a proporcionalidade e a razoabilidade apresentam-se, segundo Ávila, como postulados normativos específicos, ou seja, metanormas que indicam como será feita a aplicação das regras e princípios ao caso concreto (2005, p. 88). São nortes aos julgadores, especialmente em casos de difícil interpretação ${ }^{12}$.

Tais postulados possuem inegável matriz constitucional, ainda que implícita, já que

${ }^{10}$ Súmula 527 do STJ: O tempo de duração da medida de segurança não deve ultrapassar o limite máximo da pena abstratamente cominada ao delito praticado.

${ }^{11}$ EMENTA: EXECUÇÃO PENAL. HABEAS CORPUS. (1) IMPETRAÇÃO SUBSTITUTIVA. IMPROPRIEDADE DA VIA ELEITA. (2) SENTENÇA ABSOLUTÓRIA IMPRÓPRIA. MEDIDA DE SEGURANÇA. LIMITE DE DURAÇÃO DA MEDIDA. PENA MÁXIMA COMINADA IN ABSTRATO AO DELITO COMETIDO. (3) AUSÊNCIA DE ILEGALIDADE. TEMPO DE INTERNAÇÃO DO PACIENTE INFERIOR AO PRAZO MÁXIMO ABSTRATAMENTE COMINADO. (4) WRIT NÃO CONHECIDO. 1. É imperiosa a necessidade de racionalização do emprego do habeas corpus, em prestígio ao âmbito de cognição da garantia constitucional, e, em louvor à lógica do sistema recursal. In casu, foi impetrada indevidamente a ordem como substitutiva de recurso especial. 2. O prazo de duração da medida de segurança não deve ultrapassar o limite máximo da pena abstratamente cominada ao delito cometido. No caso em apreço, não se vislumbra manifesta ilegalidade, apta a ensejar a concessão da ordem, de ofício, uma vez que o paciente está internado há 9 (nove) anos, tempo inferior ao máximo abstratamente cominado de 13 (treze) anos e 4 (quatro) meses de reclusão. 3. Writ não conhecido. (STJ - HC: 286733 RS 2014/0007843-5, Relator: Ministra MARIA THEREZA DE ASSIS MOURA, Data de Julgamento: 25/11/2014, T6 - SEXTA TURMA, Data de Publicação: DJe 15/12/2014)

${ }^{12}$ A caracterização dos elementos de cada um dos postulados fugiria ao escopo do trabalho, ver AVILA, 2005, p. 101-127. 
norteiam, como dito, a intepretação e aplicação das normas fundamentais. A isonomia, ademais, possui expressa previsão, já no caput, do art. $5^{\circ}$, da CF, o qual declara sua irradiação para todos os dispositivos normativos subsequentes, inclusive os de matéria penal.

Já no $\mathrm{HC} \mathrm{n}^{\mathrm{o}}$ 285.953/RS ${ }^{13}$, a então Ministra Relatora Laurita Vaz também apontou como fundamento o fato de a medida de segurança ser espécie de sanção penal, pois “apresenta um caráter de retribuição ao delito cometido, bem como de prevenção a possível cometimento de novos crimes", o que faria incidir também a vedação a penas de caráter perpétuo (BRASIL, 2014, p. 11-12).

Constata-se no voto a associação da medida de segurança com as modernas teorias da pena de prisão, a saber a retributiva (absoluta) e a preventiva (relativa), o que demonstra a percepção do caráter sancionatório e aflitivo do instituto.

Esses objetivos declarados da pena, remete-nos ao histórico de desenvolvimento do próprio direito penal clássico e a limitação do poder punitivo estatal. A partir do século XVIII, garantias jurídicas das penas foram construídas de forma a contraporem-se à severidade das punições aplicadas pelos governos absolutistas do Antigo Regime (PIRES, 2001, p. 75). Trocou-se os eventuais suplícios, de livre critério do regente, pela certeza da punição com

\footnotetext{
${ }^{13}$ HABEAS CORPUS SUBSTITUTIVO DE RECURSO ESPECIAL. NÃO CABIMENTO. RESSALVA DO ENTENDIMENTO PESSOAL DA RELATORA. HOMICÍDIO SIMPLES TENTADO E HOMICÍDIO QUALIFICADO TENTADO. MEDIDA DE SEGURANÇA DE INTERNAÇÃO. PRORROGAÇÃO. DECISÃO FUNDAMENTADA. LAUDOS PERICIAIS. PERMANÊNCIA DA PERICULOSIDADE DO AGENTE. PRINCÍPIO DO LIVRE CONVENCIMENTO MOTIVADO. VEDAÇÃO CONSTITUCIONAL DE PENAS PERPÉTUAS. LIMITAÇÃO DO TEMPO DE CUMPRIMENTO AO MÁXIMO DA PENA ABSTRATAMENTE COMINADA. PEDIDO DE DESINTERNAÇÃO. IMPOSSIBILIDADE. ORDEM DE HABEAS CORPUS NÃO CONHECIDA. 1. A Primeira Turma do Supremo Tribunal Federal e ambas as Turmas desta Corte, após evolução jurisprudencial, passaram a não mais admitir a impetração de habeas corpus em substituição ao recurso ordinário, nas hipóteses em que esse último é cabível, em razão da competência do Pretório Excelso e deste Superior Tribunal tratar-se de matéria de direito estrito, prevista taxativamente na Constituição da República. 2. Esse entendimento tem sido adotado pela Quinta Turma do Superior Tribunal de Justiça, com a ressalva da posição pessoal desta Relatora, também nos casos de utilização do habeas corpus em substituição ao recurso especial, sem prejuízo de, eventualmente, se for o caso, deferir-se a ordem de ofício, em caso de flagrante ilegalidade. 3. As instâncias ordinárias constataram, com fulcro em laudos periciais, que o Paciente não está em condições de retornar ao convívio social. Em decorrência dessa constatação, decidiram pela manutenção da medida de segurança, com possibilidade de alta progressiva. 4. Consoante o disposto no art. 182 do Código de Processo Penal, o laudo pericial não vincula o magistrado, que poderá aceitá-lo ou rejeitá-lo, no todo ou em parte, desde que o faça em decisão validamente motivada, o que restou observado no caso em apreço. 5. Nos termos do atual posicionamento desta Corte, o art. 97, $\S 1 .^{\circ}$, do Código Penal, deve ser interpretado em consonância com os princípios da isonomia, proporcionalidade e razoabilidade. Assim, o tempo de cumprimento da medida de segurança, na modalidade internação ou tratamento ambulatorial, deve ser limitado ao máximo da pena abstratamente cominada ao delito perpetrado e não pode ser superior a 30 (trinta) anos, situações não ocorrentes no caso. 6 . Ordem de habeas corpus não conhecida. (STJ - HC: 285953 RS 2013/0422383-2, Relator: Ministra LAURITA VAZ, Data de Julgamento: 10/06/2014, T5 - QUINTA TURMA, Data de Publicação: DJe 24/06/2014)
} 
parâmetros.

No panorama da Revolução Francesa, as teorias clássicas da pena tiveram como precursores Beccaria e Kant. O primeiro associou a punição ao objetivo de dissuasão ou prevenção, de modo que a certeza de aplicação de uma pena moderada faria com que o indivíduo se abstivesse de cometer o crime. Já para Kant, um retribucionista, diante de um delito haveria uma obrigação moral de punir fundamentada no imperativo categórico (PIRES, 2001, p. 81). Contemporâneamente, conclui-se que ambas as propostas foram incorporadas no direito penal brasileiro, tendo em vista que o art. 59, do $\mathrm{CP}^{14}$ avoca a reprovação e prevenção como fins da pena privativa de liberdade a ser fixada.

A partir dessas considerações cunhou-se um sistema de garantias jurídicas incidentes sobre o sistema de justiça criminal, a exemplo dos princípios da legalidade, anterioridade, individualização da pena e devido processo legal. Os quais, no movimento de constitucionalização do Direito, passaram a ser objeto de proteção e difusão pela Carta Magna, como consta no extenso rol de direitos fundamentais. Sua reverberação na legislação ordinária acabou por alcançar o próprio instituto da medida de segurança, nas decisões judiciais analisadas.

Os demais precedentes que inspiraram a confecção da súmula $\mathrm{n}^{\circ} 527$ do $\mathrm{STJ}$, a saber o HC no 269.377/AL; HC n ${ }^{\circ}$ 251.296/SP; HC no 160.734/SP; HC $n^{\circ} 167.136 / D F ; H C n^{\circ}$ 91.602/SP; HC n ${ }^{\circ}$ 156.916/RS, trouxeram argumentos idênticos aos já expostos, motivo pelo qual os teores dos votos não foram mencionados neste trabalho.

Observa-se que a constitucionalização do Direito Penal, explicitada nos capítulos iniciais, seja no movimento de inclusão de normas sobre a matéria no bojo da CF, seja pela interpretação da legislação ordinária de acordo com seus objetivos, pode ser apontada como mola propulsora dos julgados do STF e STJ sobre a execução da medida de segurança, especialmente em relação à limitação de sua duração.

Segundo Barroso:

[...] algumas tipificações previamente existentes são questionáveis à luz dos novos valores constitucionais ou da transformação dos costumes, assim como podem ser excepcionadas em algumas de suas incidências concretas, se provocarem resultado constitucionalmente indesejado (2005, p. 41).

\footnotetext{
${ }^{14}$ Art. 59 do CP: O juiz, atendendo à culpabilidade, aos antecedentes, à conduta social, à personalidade do agente, aos motivos, às circunstâncias e consequiências do crime, bem como ao comportamento da vítima, estabelecerá, conforme seja necessário e suficiente para reprovação e prevenção do crime.
} 
A legislação ordinária referente à medida de segurança, confeccionada em grande parte em momento anterior à promulgação da Constituição Federal de 1988, possui pontos divergentes dos objetivos de proteção da dignidade da pessoa humana. A possibilidade da perpetuidade da restrição da liberdade do inimputável nega valores fundamentais de observância obrigatória pelo sistema criminal, responsável pela sua custódia.

Coube então ao julgador a tarefa de reinterpretar a regra penal de forma que ela se adeque ao texto constitucional e aos seus objetivos, e seja efetivamente recepcionada pela Carta Magna (CARVALHO, 2005, p. 893).

Os princípios constitucionais de isonomia, proporcionalidade e razoabilidade, bem como a regra de vedação à prisão de caráter perpétuo, foram argumentos trazidos pelos julgadores para aplicar limitação temporal à medida de segurança, e denotam a importância do processo de constitucionalização do Direito Penal na concretização desse posicionamento. Um passo a mais para alterar a realidade de um instituto esquecido pelo tempo, mas responsável pela vida de milhares de pessoas país afora.

\section{CONCLUSÃO}

A promulgação da Constituição Federal de 1988, após um momento extremamente revoltante da política brasileira, representou uma esperança de consolidação da democracia e, com ela, de um Estado de Direito comprometido com uma sociedade justa e igualitária.

O Direito Penal, enquanto instrumento de poder sobre o corpo e destino dos indivíduos, sempre foi palco para arbitrariedades e controle pelo poder estatal. Com isso, a limitação de ingerência das autoridades nesse campo sempre se mostrou como urgente. Mas, no contexto atual, outra preocupação também surge: a de promover uma vida digna a todos os envolvidos no conflito, seja para a sociedade em busca de segurança, para a vítima em busca de reparação ou para o agente na proteção de sua dignidade no momento da responsabilização. Assim, a Constituição se divide entre garantias fundamentais de aplicação das penas e mandados de criminalização para proteção de bens jurídicos que reputa de extrema importância.

Em um contexto histórico de foco na aplicação da pena de prisão pelo Estado, e em como balancear isso com os valores constitucionais de proteção do indivíduo, a medida de segurança sempre foi relegada para segundo plano. Fato este que propiciou, por muitos anos, a ausência de limitação temporal em sua execução, mesmo no contexto de vedação a penas de 
prisão perpétua.

É pela constação de que, além de ter caráter formal, a medida de segurança também possui conteúdo penal, que as normas constitucionais atinentes à pena de prisão também devem incidir sobre sua aplicação e execução. Do contrário, estar-se-ia tratando de forma mais gravosa, e sem justificativa plausível, o inimputável que, em tese, não teria como compreender o caráter ilícito de sua conduta e portar-se de acordo com a lei.

Então, o movimento de constitucionalização do Direito Penal, em especial a obrigatoriedade de reinterpretação desse ramo que ele promove, foi um dos responsáveis pelas decisões dos Tribunais Superiores acerca da limitação temporal da execução da medida de segurança. O que, ao fim, resultou na publicação da Súmula $n^{\circ} 527$ do STJ e a determinação de respeito ao prazo máximo da pena abstratamente cominada ao delito.

Esse é um passo importante para a ressignificação do tratamento penal inflingido ao portador de transtorno mental em conflito com a lei. Promove o fim de longas (e inconstitucionais) internações em instituições de caráter eminentemente asilar. Contudo, representa apena uma gota em um oceano de contradições existentes na interlocução secular entre Psiquiatria e Direito Penal.

\section{REFERÊNCIAS}

ÁVILA, Humberto. Teoria dos princípios: da definição à aplicação dos princípios jurídicos. 4 ed. São Paulo: Malheiros, 2005.

BARROSO, Luis Roberto. Neoconstitucionalismo e constitucionalização do Direito: o triunfo tardio do direito constitucional no Brasil. In: Revista de Direito Administrativo, São Paulo, v. 240, p. 1-53, 2005.

BITENCOURT, Cezar Roberto. Tratado de Direito Penal: parte geral. 22. ed. São Paulo: Saraiva, 2016. $5 \mathrm{v}$.

BRASIL. Código Penal: Decreto-lei n. 2.848, de 7 de janeiro de 1940. Institui o Código Penal. Rio de Janeiro: Presidência da República, 1940. Disponível em: http://www.planalto.gov.br/ccivil_03/decreto-lei/Del2848compilado.htm. Acesso em: 15 de maio de 2021.

BRASIL. Constituição da República Federativa do Brasil. Brasília: Senado Federal, 1988. Disponível em: http://www.planalto.gov.br/ccivil_03/constituicao/constituicao.htm1. Acesso: em 15 de maio de 2021.

BRASIL. Lei de Execução Penal: Lei n. 7.210, de 11 de julho de 1984. Institui a Lei de 
Execução Penal. Brasília: Palácio do Planalto, 1984. Disponível em: http://www.planalto.gov.br/ccivil_03/leis/L7210compilado.htm. Acesso em: 15 de maio de 2021.

BRASIL. Superior Tribunal de Justiça. Súmula n. 527. Aprovada em 13 mai. 2015. Disponível em: https://scon.stj.jus.br/SCON/sumulas/doc.jsp?livre=@ num=\%27527\%27. Acesso em: 15 de maio de 2021.

BRASIL. Superior Tribunal de Justiça. Habeas Corpus n. 285953/RS. Julgado em 15 dez. 2014. Relatora: Ministra Maria Thereza de Assis Moura. Disponível em: https://processo.stj.jus.br/processo/pesquisa/?src=1.1.3\&aplicacao=processos.ea\&tipoPesquis a=tipoPesquisaGenerica\&num_registro=201400078435. Acesso em: 15 de maio de 2021 .

BRASIL. Superior Tribunal de Justiça. Habeas Corpus n. 286733/RS. Julgado em 24 jun. 2014. Relatora: Ministra Laurita Vaz. Disponível em: https://processo.stj.jus.br/processo/pesquisa/?src=1.1.3\&aplicacao=processos.ea\&tipoPesquis $\mathrm{a}=$ tipoPesquisaGenerica\&num_registro=201304223832. Acesso em: 15 de maio de 2021 .

BRASIL. Supremo Tribunal Federal. Habeas Corpus n. 84219/SP. Julgado em 23 set. 2005. Relator: Ministro Marco Aurélio. Disponível em: https://jurisprudencia.stf.jus.br/pages/search/sjur92955/false. Acesso em: 15 de maio de 2021.

CARVALHO, Salo de. A sentença criminal como instrumento de descriminalização: o comprometimento ético do operador do Direito na efetivação da Constituição. In: SARMENTO, Daniel; SOUZA NETO, Claudio Pereira de (coord.). A constitucionalização do direito: fundamentos teóricos e aplicações específicas. Rio de Janeiro: Lumen Juris, 2007. p. 879-898.

FELDENS, Luciano. A conformação constitucional do Direito Penal: realidades e perspectivas. In: SARMENTO, Daniel; SOUZA NETO, Claudio Pereira de (coord.). A constitucionalização do direito: fundamentos teóricos e aplicações específicas. Rio de Janeiro: Lumen Juris, 2007. p. 831-856.

FÜHRER, Maximiliano Roberto Ernesto. Tratado da inimputabilidade no Direito Penal. São Paulo: Malheiros Editores, 2000.

GOFFMAN, Erving. Manicômios, prisões e conventos. São Paulo: Perspectiva, 2015.

OLIVÉ, Juan Carlos Ferré et al. Direito penal brasileiro: parte geral: princípios fundamentais e sistema. São Paulo: Revista dos Tribunais, 2011.

PILON, Almir José; DUTRA, Delamar José Volpato. Filosofia jurídica contemporânea, justiça e dignidade do ser humano: John Rawls e Ronald Dworkin. In: WOLKMER, Antônio Carlos (org). Fundamentos do humanismo jurídico no ocidente. São Paulo: Manole, 2003. p. 183-213.

PIRES, Alvaro P. La línea maginot en el derecho penal: la protección contra el crimen versus 
la protección contra el príncipe. Nueva Doctrina Penal, Buenos Aires, A, 2001, p. 71-96.

PULIDO, Carlos Bernal. O princípio da proporcionalidade da legislação penal. In: SARMENTO, Daniel; SOUZA NETO, Claudio Pereira de (coord.). A constitucionalização do direito: fundamentos teóricos e aplicações específicas. Rio de Janeiro: Lumen Juris, 2007 p. $805-830$.

SOARES, Mário Lúcio Quintão. Teoria do Estado: novos paradigmas em face da globalização. 5 ed. Minas Gerais: Arraes Editores, 2017. p. 303-306.

WEIGERT, Mariana de Assis Brasil e. Medidas de Segurança e Reforma Psiquiátrica: silêncios e invisibilidades nos manicômios judiciais brasileiros. Florianópólis: Empório do Direito, 2017.

ZAFFARONI, Eugenio Raúl; PIERANGELI, José Henrique. Manual de Direito Penal Brasileiro: volume 1, parte geral. 9 ed. São Paulo: Revista dos Tribunais, 2011. 